\title{
Dyslipidemia in young patients with type 1 diabetes mellitus
}

Thaís Kataoka Homma', Camila Matsuura Endo², Tatiana Saruhashi ${ }^{2}$, Ana Paula Ivata Mori ${ }^{2}$, Renata Maria de Noronha ${ }^{3}$, Osmar Monte 4 , Luis Eduardo Procópio Calliari ${ }^{4}$

\begin{abstract}
Objective: The association between type 1 diabetes mellitus (T1D) and dyslipidemia (DLP) increases the risk of cardiovascular disease (CVD). The aim of this study was to evaluate the presence of dyslipidemia in young T1D patients. Materials and methods: The study design was cross-sectional and descriptive. We reviewed medical records ofT1D patients followed at an endocrinology service, from 1998-2012. Data collected: gender, actual age and age at diagnosis, duration of T1D since diagnosis, body mass index (BMI), pubertal stage, glycemic control (GC) determined by glycated hemoglobin $(\mathrm{HbA} 1 \mathrm{c})$, total cholesterol (TC), HDL, LDL, triglycerides (TG). To analyze lipid profile and metabolic control, we used the Brazilian Society of Diabetes Guidelines. Results: Were included 239 T1D patients, $136(56.9 \%)$ females; mean \pm SD: actual age $15.7 \pm 5.0$ years and atT1D diagnosis $7.3 \pm 3.9 ; \mathrm{T} 1 \mathrm{D}$ duration $10.6 \pm 6.4$ years, $86.6 \%$ puberty, $15.1 \%$ overweight. The prevalence of DLP was $72.5 \%, 63.3 \%$ females, $86.6 \%$ puberty, mean \pm SD: actual age $15.4 \pm 4.8$ years and at T1D diagnosis $7.2 \pm 4.1$ years, duration of T1D $10.7 \pm 6.1$ years. We found high-CT in $56.7 \%$, low-HDL $=21.7 \%$, high LDL $=44.0 \%$, high-TG $=11.8 \%$. Between females with DLP, $83.5 \%$ was in puberty. We find correlation between the presence of DLP, a poor GC and BMC. Conclusion: We found a high prevalence of DLP in young patients with T1D, particularly in puberty females. Programs targeting the prevention of dyslipidemia should be adopted, especially for this group, in order to prevent/delay chronic complications and cardiovascular disease. Arch Endocrinol Metab. 2015;59(3):215-9
\end{abstract}

Keywords

Type 1 diabetes mellitus; dyslipidemia; atherosclerosis; cardiovascular risk
1 Pediatric Endocrinology Unit, Pediatrics Department, Irmandade da Santa Casa de Misericórdia de São Paulo (ISCMSP), São Paulo, SP, Brazil ${ }^{2}$ Santa Casa São Paulo School of Medicine, São Paulo, SP, Brazil

${ }^{3}$ Pediatrics Department, ISCMSP, São Paulo, SP, Brazil ${ }^{4}$ Pediatric Endocrinology Unit, Pediatrics Department ISCMSP and Santa Casa São Paulo School of Medicine, São Paulo, SP, Brazil

Correspondence to: Thaís Kataoka Homma Rua Martinico Prado, 128, ap. 95 01224-010 - São Paulo, SP, Brazil thais_kataoka@yahoo.com.br

Received on Apr/4/2014 Accepted on Apr/8/2015

DOI: $10.1590 / 2359-3997000000040$

\section{INTRODUCTION}

$\mathrm{T}$ he prevalence of dyslipidemia (DLP) in the general population, including children, has recently increased (1-3). Changes in lifestyle that contribute to overweight and obesity, including sedentarism and high carbohydrate and fat diets, may have contributed to this increased DLP prevalence $(1,4,5)$.

In patients with type 1 diabetes mellitus (TID), the presence of DLP significantly increases cardiovascular risk. Patients with TID have a 2-4 times greater risk of developing atherosclerosis compared to people without diabetes mellitus, and cardiovascular events account for up to $44 \%$ of the total mortality in these patients $(2,6-8)$.

However, there are few studies that have investigated the relationship between DLP and TID in young people; most of the information has been based on adult studies $(6,9-11)$. Therefore, this study aimed to determine the prevalence of DLP in young patients with TID in an endocrinology referral center.

\section{MATERIALS AND METHODS}

This retrospective study collected data from the medical records of TID patients of both genders (chronological age $\geq 5$ years) who were followed in the Diabetes Outpatient Clinic at Santa Casa School of Medicine of São Paulo (ISCMSP), São Paulo, Brazil, from 1998-2012.

The following data were collected: (1) clinical data including gender, actual age and age at TID diagnosis, duration of TID since diagnosis; weight $(\mathrm{kg})$, height $(\mathrm{cm})$, and age-specific body mass index $\left(\mathrm{BMI} ; \mathrm{kg} / \mathrm{m}^{2}\right)$; and (2) laboratory data, which were measured up to a maximum of 3 months from the appointment date, including glycemic control (GC); glycated hemoglobin [HbAlc, measured by turbidimetric immunoassay], triglycerides (TG), and total cholesterol (TC, esterase-oxidase) and its fractions (high-density lipoprotein [HDL] measured by enzymatic colorimetric method and low-density lipoprotein [LDL, estimated using the Friedewald equation]). 
Data on weight and height were analyzed and classified by using the WHO Anthro ${ }^{\circledR}$ software, Geneva, Switzerland. The $\mathrm{Z}$ score (BMI/Age) indices were used to evaluate nutritional status. Patients were classified as eutrophic $(Z,-1$ to +1$)$, overweight $(Z,+1$ to $+2)$, obese $(Z \geq 2)$ and low weight $(Z \leq-1)(12)$.

Patients were stratified according to age (5-9.9 years, 10-18.9 years, and $\geq 19$ years) and ranked on the basis of the lipid profile and metabolic control according to the recommendations of the Guidelines of the Brazilian Society of Diabetes (2013 to 2014), (13) considering normal values for children $\mathrm{TC}<150 \mathrm{mg} / \mathrm{dL}$; $\mathrm{HDL} \geq 45 \mathrm{mg} / \mathrm{dL} ; \mathrm{LDL}<100 \mathrm{mg} / \mathrm{dL} ; \mathrm{TG}<100$ $\mathrm{mg} / \mathrm{dL} ; \mathrm{HbAlc}:<7.5 \%$. The adults were considered as having normal values when $\mathrm{TC}<200 \mathrm{mg} / \mathrm{dL}$; HDL $>40 \mathrm{mg} / \mathrm{dL}$ in men; HDL $>50 \mathrm{mg} / \mathrm{dL}$ in women; $\mathrm{LDL}<100 \mathrm{mg} / \mathrm{dL} ; \mathrm{TG}<150 \mathrm{mg} / \mathrm{dL} ; \mathrm{HbAlc}:<7 \%$. DLP was considered when we have at least one of them unsettled.

Descriptive and comparative statistical analyses between the variables were conducted by using SigmaStat for Windows version 3.5 (SPSS Inc., San Jose, CA, USA).

We used relative or absolute frequency in the analysis of the qualitative variables, and mean and standard deviation for continuous data. We used teste $t$ when the analyzed variables were parametric and Mann-Whitney for non-parametric data. $\mathrm{p}<0.05$ was considered statistically significant.

The study was approved by the Ethics in $\mathrm{Hu}^{-}$ man and Animal Medical Research committee of the ISCMSP.

\section{RESULTS}

Between 1998 and 2012, 239 patients with DMl aged 5-31 years were followed. The patient's characteristics are described in table 1. Prevalence of DLP was $72.5 \%$ of the TID patients (Figure 1). We found no statistical differences in epidemiologic variables when making comparisons according to the pubertal stage (prepubertal vs. pubertal) or nutritional status (eutrophic vs. overweight) ( $\mathrm{p}>0.05$, Mann-Whitney U test).

When comparisons were conducted according to the gender, we found $81.7 \%$ of DLP in the female patients and $61.8 \%$ in males $(\mathrm{p}<0.01$, Mann-Whitney $U$ test) (Table 2). As there was a higher prevalence of DLP in the female patients, these patients were categorized according to their nutritional status (eutrophic vs. overweight) and presence of DLP (presence or absence). Overweight status did not contribute to poorer GC (p: 0.56, Mann-Whitney $U$ test), but it was associated with a higher prevalence of DLP $(\mathrm{p}<0.01$, Mann-Whitney $U$ test). The lipid profile when analyzed separately (CT, HDL, LDL, TG) was unrelated with overweight ( $\mathrm{p}>0.05$, Mann-Whitney $U$ test).

When we analyzed the presence of DLP in the female group considering the puberty stage, it was more prevalent in pubertal girls $(82.7 \%)(\mathrm{p}<0.01$; Mann-Whitney $U$ test); however, was unrelated to age (p: 0.33, Mann-Whitney $U$ test), age at TID diagnosis (p: 0.48 , Mann-Whitney $U$ test), disease duration (p: 0.52, Mann-Whitney $U$ test) or glycemic control (p: 0.56, Mann-Whitney $U$ test). From all the patients that had DLP and were in puberty, $63.3 \%$ were female.

When we analyzed the frequency of DLP and lipid prolife according the age groups TID patients, the group aged $\geq 19$ years had more DLP $(66.1 \%)$ with greater levels of TC (21.4\%) ( $<<0.01$; Mann-Whitney $U$ test) than the other age groups. There was no statistical difference between the other age groups (5-9.99 years) vs. (10-18.99 years) ( $\mathrm{p}>0.05$, Mann-Whitney $U$ test). The patient's characteristics (mean $\pm \mathrm{DP}$ ) by age group and gender are described in table 3 .

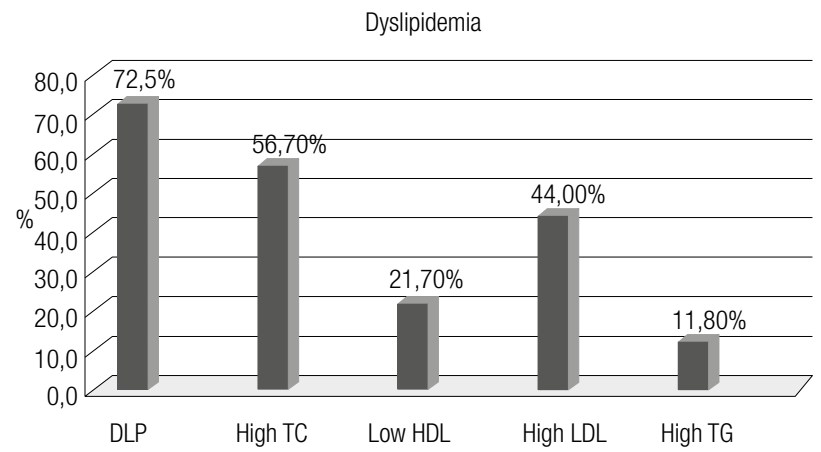

Figure 1. Prevalence of dyslipidemia in patients with type 1 diabetes mellitus at the Department of Endocrinology ISCMSP, 1998-2012.

Table 1. Characteristics of the patients with type 1 diabetes mellitus (T1D) at the Department of Endocrinology ISCMSP, 1998-2012

\begin{tabular}{lc}
\hline Group characteristics & Total $(\mathbf{n}=\mathbf{2 3 9})$ \\
\hline Gender, $\mathrm{n}(\%)$ & 136 Females (56.9); 103 Males (43.1) \\
Actual age - years (SD) & $15.7 \pm 5.0$ \\
Age at T1D diagnosis - years (SD) & $7.3(4.0)$ \\
Disease duration - years (SD) & $10.6(6.4)$ \\
Puberty, $\mathrm{n}(\%)$ & $206(86.6)$ \\
Eutrophic, $\mathrm{n}(\%)$ & $139(72.0)$ \\
Overweight /obese, $\mathrm{n}(\%)$ & $27(15.1)$ \\
Low weight, $\mathrm{n}(\%)$ & $18(13.0)$ \\
\hline
\end{tabular}


Table 2. Clinical and laboratory characteristics by gender in patients with type 1 diabetes mellitus at the Department of Endocrinology ISCMSP, 19982012

\begin{tabular}{|c|c|c|c|}
\hline Characteristics & Female & Male & $\mathbf{P}$ \\
\hline$N=239$ & $N=136(\%)$ & $N=103(\%)$ & \\
\hline Actual age - years (SD) & $15.7( \pm 5.3)$ & $15.7( \pm 4.5)$ & 0.94 \\
\hline Disease duration - years (SD) & $10.5( \pm 6.3)$ & $10.7( \pm 6.5)$ & 0.72 \\
\hline Overweight, n (\%) & $26(19.1)$ & $10(9.7)$ & $0.04^{*}$ \\
\hline Pubertal group, n (\%) & $116(85.3)$ & $90(87.4)$ & $<0.01^{*}$ \\
\hline Poor glycemic control, n (\%) & $121(93.0)$ & $86(86.7)$ & 0.17 \\
\hline DLP, n (\%) & $107(81.7)$ & $62(60.8)$ & $<0.01^{*}$ \\
\hline High TC, n (\%) & $87(66.9)$ & $44(43.6)$ & 0.18 \\
\hline Low HDL, n (\%) & $32(23.1)$ & $18(20.0)$ & ${ }^{*} 0.04$ \\
\hline High LDL, n (\%) & $70(50.4)$ & $31(35.6)$ & 0.06 \\
\hline High TG, n (\%) & $19(14.8)$ & $8(8.0)$ & 0.49 \\
\hline
\end{tabular}

${ }^{*} p<0.05$; Mann-Whitney Utest.

Table 3. Clinical and laboratory characteristics (mean \pm SD) by gender and age in patients with type 1 diabetes mellitus at the Department of Endocrinology ISCMSP, 1998-2012

\begin{tabular}{|c|c|c|c|c|c|c|c|c|c|}
\hline \multirow{2}{*}{$\begin{array}{l}\text { Characteristics } \\
\mathrm{N}=\mathbf{2 3 9}\end{array}$} & \multicolumn{3}{|c|}{$\begin{array}{c}5-9,9 \text { years } \\
\text { mean } \pm S D\end{array}$} & \multicolumn{3}{|c|}{$\begin{array}{c}10 \text { - 18,9 years } \\
\text { mean } \pm \text { SD }\end{array}$} & \multicolumn{3}{|c|}{$\begin{array}{l}\geq 19 \text { years } \\
\text { mean } \pm S D\end{array}$} \\
\hline & $N=33$ & $F=25$ & $M=8$ & $N=152$ & $F=76$ & $M=76$ & $\mathrm{~N}=54$ & $F=35$ & $M=19$ \\
\hline Actual age-years & $8.3(1.1)$ & $8.2(1.2)$ & $8.4(0.9)$ & $14.9(2.4)$ & $15.0(2.2)$ & $14.7( \pm 2.6)$ & $22.6(3.2)$ & $22.6(3.4)$ & $22.6(3.0)$ \\
\hline Disease duration - years & $5.8(4.5)$ & $6.1(4.5)$ & $5.0(4.7)$ & $9.8(5.6)$ & $9.6(5.1)$ & $10,1( \pm 6.0)$ & $15.8(6.1)$ & $15.7(6.4)$ & $15.9(5.7)$ \\
\hline z BMl & $0.4(0.4)$ & $0.5(1.1)$ & $0.2(1.9)$ & $0.3(1.1)$ & $0.3(1.1)$ & $0.1( \pm 1.0)$ & $0.1(0.9)$ & $0.1(0.9)$ & $0.1(1.2)$ \\
\hline $\mathrm{Hb} 1 \mathrm{Ac}(\%)$ & $9.0(1.9)$ & $9.1(1.9)$ & $8.5(2.0$ & $11(2.5)$ & $11.6(2.5)$ & $10.5( \pm 2.5)$ & $10.2(2.6)$ & $10.5(3.0)$ & $9.5(1.8)$ \\
\hline TC & $162.4(35.5)$ & $158.6(29.3)$ & $172.1(49.5)$ & $168.2(40.6)$ & $184.0(42.1)$ & $152.4( \pm 32.3)$ & $177.1(50.8)$ & $186.6(57.3)$ & $159.6(29.7)$ \\
\hline HDL & $49.8(9.9)$ & $50.2(10.4)$ & $48.3(8.7)$ & $52.3(12.2)$ & $55.1(12.5)$ & $49.4( \pm 10.7)$ & $51.4(13.5)$ & $53.7(14.9)$ & $47.1(9.4)$ \\
\hline LDL & $97.1(32.2)$ & $94.2(28.6)$ & $104.8(41.4)$ & $99.9(31.8)$ & $110.9(33.9)$ & $88.8( \pm 25.3)$ & $103.6(39.4)$ & $110.4(42.8)$ & $91.2(29.4)$ \\
\hline TG & $70.3(47.4)$ & $62.5(26.4)$ & 89.9 (78.5) & $87.2(55.2)$ & $100.8(66.7)$ & $73.7( \pm 36.2)$ & $103.0(56.4)$ & $104.3(55.6)$ & $100.6(59.3)$ \\
\hline Total Daily Insulin (U//kg/day) & $0.9(0.4)$ & $1.0(0.4)$ & $0.9(0.4)$ & $1.2(0.4)$ & $1.2(0.4)$ & $1.1(0.4)$ & $0.9(0.4)$ & $0.8(0.4)$ & $1.0(0.2)$ \\
\hline
\end{tabular}

F: female; M: male; BMl: body mass index; HbA1c: glycated hemoglobin; TC: total cholesterol; HDL: high-density lipoprotein; LDL: low-density lipoprotein; TG: triglycerides.

\section{DISCUSSION}

We found a high prevalence of DLP (72.5\%) in young patients with TID, characterized primarily by increased TC and LDL levels. The increased prevalence of DLP has previously been reported, even among young patients $(1-3,14)$. However, the prevalence in the present study was much higher than that found by Polak and cols., who reported that $16 \%$ of puberal patients with TID had elevated TC, while 5\% had hypertriglyceridemia (15).

Regarding the atherogenic profile, the most commonly reported forms of DLP in patients with TID include elevated TC, LDL, and TG values $(4,6,9)$ which are similar to the findings observed in the present study.

There was no correlation between poor GC and HDL, LDL, TC or the TG levels, similar to those re- ported by Teles and Fornés (16). However, the results reported by Guy and cols. (14) and Giuffrida and cols. (17), in which they reported correlation between poor HbAlc levels and he presence of DLP, were different from the present findings.

According to Alves and cols. (6), DLP is most likely to be found in newly diagnosed individuals with diabetes mellitus, those who are metabolically decompensated, or patients experiencing diabetic ketoacidosis. Patients with diabetes mellitus and good GC generally have a normal lipid profile, similar to that in individuals without diabetes mellitus (14).

We observed a higher prevalence of DLP (81.7\%) with lower levels of HDL (23.1\%) in female patients. Franca and Alves (18) also reported a higher incidence of DLP in this group (34.7\%) in comparison with 
male participants (25.3\%). According to Pérez and cols. (9), even when women with TID have well-controlled glucose levels, they have a higher atherogenic profile than men, suggesting that TID has a greater impact on cardiovascular risk in women than in men. Furthermore, we did not detect a correlation between obesity/ overweight with poor metabolic control and the lipid profile in the female patients, which also suggests that the female gender can be, itself, a risk factor for DLP in TID young patients.

The findings of the present study also indicated that the atherogenic profile was poorer in pubertal patients. The studies by Polak and cols. (15), Franca and Alves (18) support this finding.

There were no differences considering the age in the total sample; however, the patients aged 10-18.9 years had more DLP and higher TC than the others groups.

Of the present sample, $15.1 \%$ were overweight or obese, of which $12.6 \%$ were overweight, and $2.5 \%$ obese. Compared to other reports based on national data, similar rates were reported by Liberatore Jr. and cols. (19), where $15.6 \%$ were overweight or obese.

The incidence of obesity is increasing in all age groups $(20)$, even among patients with $\operatorname{TlD}(21,22)$. The etiology of obesity is multifactorial, resulting from an imbalance between caloric intake and energy expenditure associated with genetic, environmental, and behavioral factors, such as a sedentary lifestyle, imbalanced diets, and increased food intake. In addition, excessive weight gain has been observed in TID patients undergoing intensive insulin therapy $(5,19,23)$.

Obesity is associated with several endocrine and metabolic comorbidities, including type 2 diabetes mellitus, hypertension, and DLP, and is considered an independent risk factor for increased mortality $(5,22,24)$. In the present study, we found an association between overweight and DLP, however we found no correlation between BMI and poor GC or lipid profile.

Better GC is associated with improved survival in patients with TlD, leading to progressive changes in the causes of mortality, particularly cardiovascular disease; therefore, it is important to identify the risk factors for cardiovascular disease in this population (25-31).

On the basis of the results of the present study, we can conclude that higher rates of DLP are present in TID adolescents, particularly associated to puberty, overweight and female gender. Early identification of DLP in this at-risk group may help to prevent or delay the onset of cardiovascular disease.
Acknowledgments: Pediatric Endocrinology Unit, Irmandade da Santa Casa de Misericórdia de São Paulo.

Disclosure: no potential conflict of interest relevant to this article was reported.

\section{REFERENCES}

1. Giuliano ICB, Caramelli B. Dislipidemias na infância e na adolescência. Pediatria. 2008;29(4):275-85.

2. Lemkes BA, Hermanides J, Devries JH, Holleman F, Meijers JC, Hoekstra JB. Hyperglycemia: a prothrombotic factor? J Thromb Haemost. 2010;8(8):1663-9.

3. Boni A, Pugliese C, Chiantelli-Cláudio C, Patin RV, Oliveira FLC. Vitaminas antioxidantes e prevenção da arteriosclerose na infância. Rev Paul Pediatr. 2010;28(4):373-80.

4. Arcanjo CL, Piccirillo LJ, Machado IV, de Andrade Jr CRM, Clemente EL, Gomes MB. Avaliação de dislipidemia e de índices antropométricos em pacientes com diabetes mellitus tipo 1. Arq Bras Endocrinol Metab. 2005;49(6):951-8.

5. Minges KE, Whittemore R, Grey M. Overweight and obesity in youth with type 1 diabetes. Annu Rev Nurs Res. 2013;31:47-69. .

6. Alves C, Veiga S, Souza T. Dislipidemia e risco de doença cardiovascular em crianças e adolescentes com diabetes melito tipo 1. Rev Paul Pediatria. 2007;25(1):82-9.

7. Tomkin $\mathrm{GH}$. Targets for intervention in dyslipidemia in diabetes. Diabetes Care. 2008;31(Suppl. 2):S241-8.

8. Schnell O, Cappuccio F, Genovese S, Standl E, Valensi P, Ceriello A. Type 1 diabetes and cardiovascular disease. Cardiovasc Diabetol. 2013;12:156.

9. Pérez A, Wägner AM, Carreras G, Giménez G, Sánchez-Quesada JL, Rigla M, et al. Prevalence and phenotypic distribution of dyslipidemia in type 1 diabetes mellitus: effect of glycemic control. Arch Intern Med. 2000;160(18):2756-62.

10. Wadwa RP, Kinney GL, Maahs DM, Snell-Bergeon J, Hokanson JE, Garg SK, et al. Awareness and treatment of dyslipidemia in young adults with type 1 diabetes. Diabetes Care. 2005;28(5):51-6.

11. Sullivan DR, Lewis B. Lipoproteins in diabetes mellitus. Laboratory Assessment of Lipoproteins in Diabetes. Contemporary Diabetes 2014;1-10.

12. World Health Organization. Department of Nutrition for Health and Development. WHO child growth standards: length/heightfor-age, weight-for-age, weight-for-length, weight-for-height and body mass index-for-age: methods and development. 2006. Available from: http://www.who.int/iris/handle/10665/43413. Accessed on: Feb 4, 2014.

13. Sociedade Brasileira de Diabetes. Diretrizes da Sociedade Brasileira de Diabetes 2013-2014. 3th ed. GEN S/A; 2013. 400 p.

14. Guy J, Ogden L, Wadwa RP, Hamman RF, Mayer-Davis EJ, Liese $A D$, et al. Lipid and lipoprotein profiles in youth with and without type 1 diabetes: the SEARCH for Diabetes in Youth case-control study. Diabetes Care. 2009;32(3):416-20.

15. Polak M, Souchon PF, Benali K, Tubiana-Rufi N, Czernichow P.Type 1 diabetic children have abnormal lipid profiles during pubertal years. Pediatr Diabetes. 2000;1(2):74-81.

16. Teles SAS, Fornés NS. Consumo alimentar e controle metabólico em crianças e adolescentes portadores de diabetes melito tipo 1. Rev Paul Pediatr. 2011;29(3):378-84.

17. Giuffrida FM, Guedes AD, Rocco ER, Mory DB, Dualib P, Matos OS, et al.; Brazilian Type 1 Diabetes Study Group (BrazDiab1SG). Heterogeneous behavior of lipids according to $\mathrm{HbA1c}$ levels undermines the plausibility of metabolic syndrome in type 1 diabetes: data from a nationwide multicenter survey. Cardiovasc Diabetol. 2012;11:156. 
18. Franca E, Alves JGB. Dislipidemia entre crianças e adolescentes de Pernambuco. Arq Bras Cardiol. 2006;87(6):722-7.

19. Liberatore Junior RR, Cardoso-Demartini AA, Ono AHA, Andrade GC. Prevalência de obesidade em crianças e adolescentes com diabetes melito tipo 1. Rev Paul Pediatr. 2008;26(2):142-5.

20. Instituto Brasileiro de Geometria e Estatística (IBGE). Antropometria e estado nutricional de crianças, adolescentes e adultos no Brasil [database on the Internet]. 2008-2009 cited. Available from: http://www.ibge.gov.br/home/estatistica/populacao/condicaodevida/pof/2008_2009_encaa/comentario.pdf. Accessed on: Mar 7, 2014.

21. Cardoso-Demartini AA, Ono AHA, de Andrade GC, Liberatore Jr RR. Prevalência de obesidade em crianças e adolescentes com diabetes melito tipo 1. Rev Paul Pediatr. 2008;26(2):142-5.

22. Conway B, Miller RG, Costacou T, Fried L, Kelsey S, Evans RW, et al. Temporal patterns in overweight and obesity in type 1 diabetes. Diabet Med. 2010;27(4):398-404.

23. Sibley SD, Palmer JP, Hirsch IB, Brunzell JD. Visceral obesity, hepatic lipase activity, and dyslipidemia in type 1 diabetes. $\mathrm{J}$ Clin Endocrinol Metab. 2003;88(7):3379-84.

24. Moraes CM, Portella RB, Pinheiro VS, Oliveira MMS, Fuks AG, Cunha $E F$, et al. Prevalência de sobrepeso e obesidade em pacientes com diabetes tipo 1. Arq Bras Endocrinol Metab. 2003;47(6):677-83.
25. Warsy AS, el-Hazmi MA. Diabetes mellitus, hypertension and obesity--common multifactorial disorders in Saudis. East Mediterr Health J. 1999;5(6):1236-42.

26. Nishimura R, LaPorte RE, Dorman JS, Tajma N, Becker D, Orchard TJ, et al. Mortality trends in type 1 diabetes. Diabetes Care. 2001;24(5):823-7.

27. Matheus ASM, Cobas RA, Gomes MB. Dislipidemias no diabetes melito tipo 1: abordagem atual. Arq Bras Endocrinol Metab [online]. 2008;52(2):334-9.

28. Wajchenberg BL, Rassi N, Feitosa AC, Lerário AC, Betti RT. Cardiovascular disease in type 1 diabetes mellitus. Arq Bras Endocrinol Metabol. 2008;52(2):387-97.

29. Maahs DM, West NA, Lawrence JM, Mayer-Davis EJ. Epidemiology of type 1 diabetes. Endocrinol Metab Clin North Am. 2010;39(3):481-97.

30. Möllsten A, Svensson M, Waernbaum I, Berhan Y, Schön S, Nyström L, et al.; Swedish Childhood Diabetes Study Group; Diabetes Incidence Study in Sweden; Swedish Renal Registry. Cumulative risk, age at onset, and sex-specific differences for developing end-stage renal disease in young patients with type 1 diabetes: a nationwide population-based cohort study. A Nationwide Population-Based Cohort Study. Diabetes. 2010;59(7):1803-8.

31. Lin YC, ThùyTD, Wang SY, Huang PL. Type 1 diabetes, cardiovascular complications and sesame. JTradit Complement Med. 2014;4:36-41. 